\title{
Experience Satisfaction and Buying intention of Exhibition Experience: An Empirical Study
}

\author{
Seung-Wan Ju and Lee-Sang Jung* \\ Department of Business Administration, Tong-Myung University, Sinsun-Ro 428, \\ Nam-gu, Busan, Korea \\ lsjung@tu.ac.kr (Corresponding author)
}

\begin{abstract}
This the research was conducted to examine how the exhibition experience at the Corporate Information Exhibition Center affects experience satisfaction in order to present the need for corporate promotion exhibitions and future development directions. As a result of conducting research and analysis, three of the four subcomponents of the exhibition experience have been proven to significantly affect the satisfaction of the experience. In addition, since entertainment experience, educational experience, and deviant experience of the experience after the offline exhibition experience increased the experience, the higher the three factors, the more the purchase result is. The results of the empirical analysis mean that the enterprise public relations exhibition hall should pay more attention to design, color, and lighting, which are aesthetics, and that active exhibition participation is more important than passive exhibition participation by visitors. Therefore, they should make efforts to enhance the experience of visitors and lead to corporate image, brand value and positive action. In order to provide the best exhibition experience for visitors, the followup study needs to be conducted by adding various variables such as customer contact information desk and guide method.
\end{abstract}

Keywords: Exhibition, company promotion exhibition hall, exhibition experience, empirical economic theory, satisfaction of experience

\section{Introduction}

Corporate marketing exhibition hall is not the place where its purpose is targeted towards only to marketing; it is becoming a complex cultural space where it not only has exhibition space, but also has experience and study. Based on its exhibition experience satisfaction and community cultural formation, corporate marketing exhibition hall is being used to enhance the image of the corporation, and management strategy for brand asset. 
In addition, it is also stimulating potential customers' purchase desire by providing new, advanced experience through high-end exhibition technique to introduce corporate's image and its products.

Therefore, corporate marketing exhibition hall is becoming more important, as it is leading customers' purchase behavior, brand asset management, and corporate image of the companies that are making efforts to manage long term customers and ever changing customer satisfaction. However, the awareness and research about corporate marketing exhibition is insufficient, and the empirical study about its effect is also very lacking.

Therefore, its research has focused on the effects of exhibition experience on the experience satisfaction and purchase intent. By doing this, it suggests any improvement plan through its exhibition experience, and any developmental direction of the corporate marketing exhibition hall. It needs to be developed into a place where it can satisfy many different needs of customers via increased communication and familiarity amongst the industries. It also needs to be developed into a place where the it can provide cultural service to the customers and potential audience via high tech exhibition technique, and a place where it can contribute to the community's culture. This study focuses on the ways to cause purchase behavior, enhance corporations' image, secure potential customers through corporate marketing exhibition hall.

\section{Theoretical Backgrounds}

Exhibition. The dictionary definition of exhibition is "putting and showing many different items in one place", and it can be an act of sharing with the audience through displaying with the exhibition planner's interpretation. In addition, it is defined to be a performance that causes meaningful share between the audience and the exhibited object, by forming a new communication system. Exhibition is not a simple display; it is a creative way to communicate and it is an active way to deliver a certain message in a certain way.

Table. 1: The Concept of Exhibition and Display

\begin{tabular}{|c|c|c|}
\hline & Exhibition & Display \\
\hline Origin & Exhibition or Exposition & $\begin{array}{c}\text { Latin word "Displicare"(Appear, } \\
\text { Open, Display) }\end{array}$ \\
\hline Expression & English - Exhibition & $\begin{array}{c}\text { English - Display(Unfold, } \\
\text { Express, Show) }\end{array}$ \\
\hline Content & Works such as painting & Goods, Work, Products \\
\hline Purpose & Nonprofit, Community Service & Commercial \\
\hline
\end{tabular}


Exhibition place is normally divided into permanent and non-permanent exhibition place. Permanent exhibitions include museums, promotion halls, and art galleries, etc., which has a main purpose to collect, store, and deliver information and is exhibited for long term.

Table. 2: Classification by Exhibition Space

\begin{tabular}{|c|c|c|}
\hline Classification & Name & Characteristics \\
\hline \multirow{4}{*}{$\begin{array}{l}\text { Permanent } \\
\text { Exhibition }\end{array}$} & Museum & $\begin{array}{l}\text { A facility with a purpose to contribute to the } \\
\text { community's education and academic research, through } \\
\text { collecting, preserving, displaying and exhibiting } \\
\text { archaeological data, historical relics and arts, etc. }\end{array}$ \\
\hline & $\begin{array}{l}\text { Promotion } \\
\text { Hall }\end{array}$ & $\begin{array}{l}\text { An exhibition space to introduce corporation's image, } \\
\text { history, manufactured products and technology, etc. }\end{array}$ \\
\hline & Memorial & $\begin{array}{l}\text { An exhibition space to commemorate a great historical } \\
\text { figure or historically significant event. }\end{array}$ \\
\hline & $\begin{array}{l}\text { Science } \\
\text { Museum }\end{array}$ & $\begin{array}{l}\text { An exhibition to introduce science related facts through } \\
\text { viewing, experiencing, and experimenting with installed } \\
\text { exhibition that were made based on scientific data or } \\
\text { theory. }\end{array}$ \\
\hline \multirow{3}{*}{$\begin{array}{l}\text { Non- } \\
\text { permanent } \\
\text { Exhibition }\end{array}$} & EXPO & $\begin{array}{l}\text { It is a world EXPO where information or technology } \\
\text { about art, science and industry, etc. are exhibited, which } \\
\text { can lead to enhance promotion of the industry and } \\
\text { expanding trade. }\end{array}$ \\
\hline & Trade Show & $\begin{array}{c}\text { This has a strong commercial characteristic. Most } \\
\text { exhibitions held at Seoul COEX, Seoul Trade } \\
\text { Exhibition Center and Busan's BEXCO, etc. are trade } \\
\text { shows. }\end{array}$ \\
\hline & Fair & $\begin{array}{l}\text { The main purpose is deals and trade. It has a strong } \\
\text { market meaning and comprises of many different parts, } \\
\text { including regional, industry, local, domestic, } \\
\text { international, etc. }\end{array}$ \\
\hline
\end{tabular}

Definition of Exhibition for Corporations. According to the intended purpose, the definition of exhibition for corporations can be into four different areas: communication, promotion, marketing, and design.

Firstly, in the communication view, exhibition means a two-way communication between the sender and the receiver. Modern community is actively using exhibition to make direct communication between the corporation and the 
consumer possible, and by checking the response at site, it provides an opportunity to form a good relationship with the consumers.

Secondly, in the promotion view, exhibition means a place where the corporation can show its image and their manufacturing products at the same time. Since the audience can directly experience and see with their own eyes, it is more persuasive, and it can also build a stronger trust regarding the corporation's image.

Thirdly, in the marketing view, exhibition means a high-end industry where various marketing technique is aggregated. Instead of visiting each consumers, exhibition brings all of them in one place, making it easier to gain such marketing effect.

Fourthly, in the design view, exhibition means a space design that delivers corporation's intended purpose for a designation period. It is a space design that has all of four elements: exhibition materials, exhibition period, visitors and exhibition space. Therefore, its artistic effect is much more emphasized.

Corporation Promotion Exhibition Hall. Corporation promotion exhibition halls are installed and operated by the corporation, and is included in the corporation museum range. According to the classification regulated by the museum law, corporation museums include science museums, industrial technology museums, history museum or folk museums. It is a professional museum that specializes in detailed collections.

The role of corporation promotion exhibition halls is: firstly, to take the role of local or nation's government to build museums for promotion of people's welfare and enhance its culture and develop the nation's culture instead.

Secondly, to contribute to enhance the corporation's image by providing the nation and the customer about educational information, with its effort to perform its social responsibility to develop the nation's culture.

Thirdly, to provide educational space for common people and customers by delivering education information.

Fourthly, to expect the establishment of corporation's image and increased reliability, which secures potential customers, build a good consumption culture, and establish a proper relationship between the corporation and the consumer.

Fifthly, to expect an increased work motivation by delivering the employees the corporation's philosophy, business management, corporation's vision, etc.

Exhibition Experience. Scholars have different opinions regarding the experience. Ancient philosopher Platon said that experience should be completely separated from notion and be limited to the world of material phenomenon. It should be seen as temporary fantasy and be exempt from true knowledge. In addition, Maslow(1994) defined experience as an enjoyable state of mind after experiencing something, and Van Maneb(1994) defined it as a recognizable state of 
mind after experiencing something.

By providing positive feeling and internal desire of the consumers, experience can lead to voluntary physical participation of the consumers and can be explained in various concepts, including new, enjoyment, fun, awakening, enhancement of social life, escaping from reality, acquiring knowledge, etc.

Experience in exhibition means having delivered, understand, and recognize its intent through directly or indirectly participating or performance.

Experience Economics Theory. The Article 'Welcome to the Experience Economy' in Harvard Business Journal in 1998 sought ways to increase commodity values. Pine \& Gilmore argued that in order to prevent products from becoming a general-purpose product in the war with competitors, it needs to add value called experience in its product or service.

Pine \& Gilmore(1998) argued that modern community has become an Experience Economy, and explained that there is a close relationship with the natural transition process of economical value, which consists of characteristics of economical products, general goods, products, service, and experience.

In addition, regarding one's experience, Pine \& Gilmore(1998) presented 4Es theory(Entertainment, Education, Escapist, Esthetics) based on two dimensions: degree of participation and relationship with the environment.

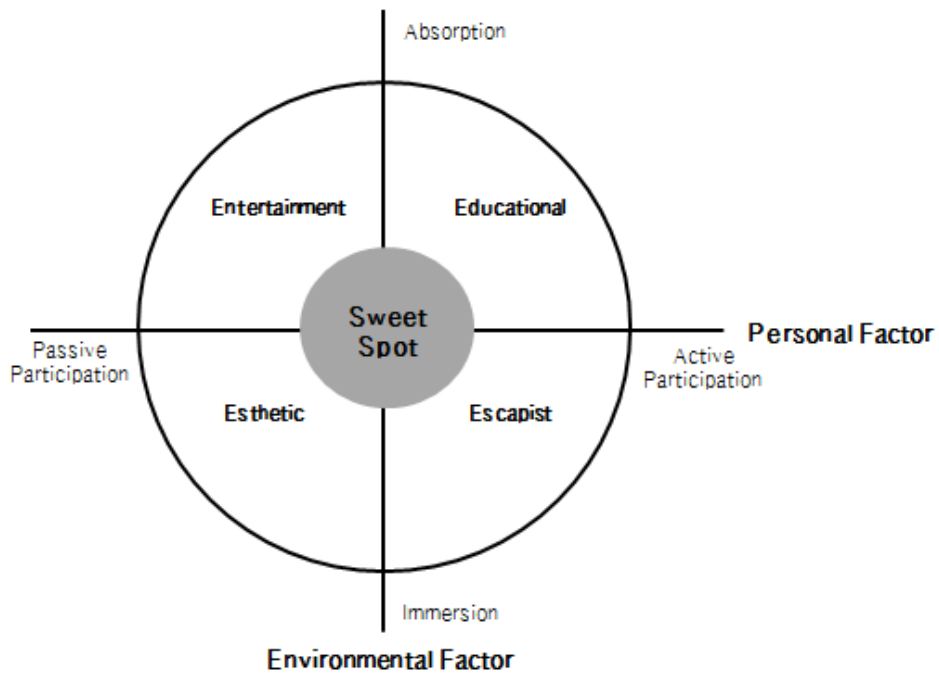

Fig. 1: Pine \& Gilmoe's Experience Components

Experience Satisfaction. The concept of satisfaction is developed from psychology. Its dictionary definition means a state of being satisfied, without any lacking element. The concept of satisfaction has long been defined by many scholars in business and tourism area. 
General idea of corporate promotion exhibition halls are evaluated by the satisfaction of the audience. Experience satisfaction is a consumption related to the achievement; therefore, it is a judgment regarding the consumption level related to the achievement of the consumer satisfaction.

The satisfaction of the audience is also having a great effect on the performance index of the corporate promotion exhibition hall. The audience means all of those who views the corporate promotion exhibition hall, and those that can have effect on substantial, potential purchase intention.

Purchase Intention. Any personal behavior is directly affected by the degree of willingness to perform such act; therefore, we focused on the importance of the intent before the purchase behavior. Purchase intent is a very important factor in purchase decision, as it can estimate the attitude and subjective norm regarding such act.

Purchase intent is defined as a person's rational judgment dimension, as it is person's will and belief that are shown with future behavior after forming an attitude regarding a certain status. In addition, purchase intention, in psychological dimension, is a comprehensive evaluation of the brand, including a desire to purchase, recommendation, availability, consideration, etc.; therefore, it is a psychological attitude derived from a person's willingness to buy.

\section{Research Design}

Subject and Research Models. In order to conduct this research, we conducted a survey targeted towards the audience who visited the corporate promotion exhibition hall and has experienced the exhibition. Based on literature and precedent research, we have set the following research model in Fig. 2 to review the effects the exhibition experience has onto the experience satisfaction and purchase intent.

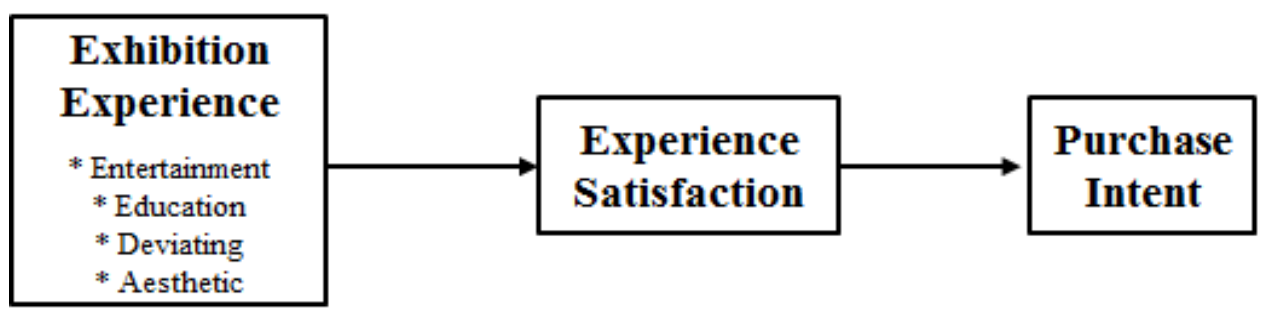

Fig. 2: Research Model.

Research Hypothesis. In this research, we aim to verify the following hypothesis based on the premise that corporate promotion exhibition halls and exhibition experience will have a positive effect on the experience satisfaction and purchase intent. 
Hypothesis 1 Exhibition experience will have a positive effect on experience satisfaction.

1-1 Entertainment experience of the exhibition experience will have a positive effect on experience satisfaction.

1-2 Educational experience of the exhibition experience will have a positive effect on experience satisfaction.

1-3 Deviating experience of the exhibition experience will have a positive effect on experience satisfaction.

1-4 Aesthetic experience of the exhibition experience will have a positive effect on experience satisfaction.

Hypothesis 2 Experience satisfaction after exhibition experience will have a positive effect on purchase intent.

\section{Empirical Analysis}

Validity and Reliability. The KMO measure regarding the exhibition experience showed .727, and Bartlett's sphere formation check was 4007.358. The probability of significance showed .000 and rejected the null hypothesis; therefore, it has been shown that it is appropriate for factor analysis in Table 3.

The reliability criteria Chonbach's- $\alpha$ value showed 0.900 for entertainment experience, 0.865 for educational experience, 0.736 for deviating experience, and 0.736 for aesthetic experience. All of those were higher than .07 , which is internal consistency evaluation value; which showed that there is an internal consistency.

Table. 3: KMO \& Bartlett Spherical Test of Exhibition Experience

\begin{tabular}{|c|c|c|}
\hline \multicolumn{2}{|c|}{ KMO measurement of the standard formation validity } & .727 \\
\hline \multirow{2}{*}{$\begin{array}{c}\text { KMO \& Bartlett Spherical } \\
\text { Test }\end{array}$} & Approximate chi-squared & 4007.358 \\
\cline { 2 - 3 } & Degree of freedom & .105 \\
\cline { 2 - 3 } & P-value & .000 \\
\hline
\end{tabular}

In addition, KMO measure regarding the experience satisfaction and purchase intent showed .854, and Bartlett's sphere formation check was 2281.379. The probability of significance showed .000 and rejected the null hypothesis; therefore, it has been shown that it is appropriate for factor analysis in Table 4.

The reliability criteria Chonbach's- $\alpha$ value showed .817 for experience satisfaction, .945 for purchase intent; this showed that there is an internal consistency. 
Table. 4: KMO \& Bartlett Spherical Test of Experience Satisfied and Buying Intention

\begin{tabular}{|c|c|c|}
\hline \multicolumn{2}{|c|}{ KMO measurement of the standard formation validity } & .854 \\
\hline \multirow{2}{*}{$\begin{array}{c}\text { KMO \& Bartlett } \\
\text { Spherical Test }\end{array}$} & Approximate chi-squared & 2281.397 \\
\cline { 2 - 3 } & Degree of freedom & .28 \\
\cline { 2 - 3 } & P-value & .000 \\
\hline
\end{tabular}

Hypothesis Test. To prove hypothesis 1 regarding the relationship between exhibition experience and experience satisfaction, we have conducted multiple regression analysis, and according to Table 5's analysis, the estimated $\mathrm{F}$ value is 94.037, which is statistically significant in significance level $\mathrm{p}<.001$. R square was 0.579 , which explains that there is $57.9 \%$ of experience satisfaction for visiting exhibition experience such as entertainment, educational, deviating, aesthetic experience, etc. In addition, all the VAF of independent variables are less than the standard 10; which means that there is no problem regarding multicollinearity amongst the independent variables.

Table. 5: Analysis results of Exhibition Experience and Experience Satisfied

\begin{tabular}{|c|c|c|c|c|c|c|c|c|c|c|}
\hline \multirow[t]{2}{*}{ Model } & \multicolumn{2}{|c|}{$\begin{array}{c}\text { Non-standar- } \\
\text { dization } \\
\text { Factor }\end{array}$} & \multirow{2}{*}{$\begin{array}{c}\begin{array}{c}\text { Standar- } \\
\text { dization } \\
\text { Factor }\end{array} \\
\text { Beta }\end{array}$} & \multirow[t]{2}{*}{$\mathbf{t}$} & \multicolumn{2}{|c|}{$\begin{array}{c}\text { Collinearity } \\
\text { Statistic }\end{array}$} & \multirow{2}{*}{$\begin{array}{c}\text { Analysis } \\
\text { of } \\
\text { F }\end{array}$} & \multirow{2}{*}{$\begin{array}{c}\text { R } \\
\text { Square }\end{array}$} & \multirow{2}{*}{$\begin{array}{c}\mathbf{R} \\
\text { Square } \\
\text { Variat- } \\
\quad \text { ion }\end{array}$} & \multirow{2}{*}{$\begin{array}{c}\text { Durbin } \\
\text { - } \\
\text { Watson }\end{array}$} \\
\hline & B & $\begin{array}{c}\text { Standard } \\
\text { Error }\end{array}$ & & & Tolerance & VIF & & & & \\
\hline (Constant) & .711 & .212 & & 3.353 & & & \multirow{5}{*}{$\begin{array}{c}94.039 \\
* * *\end{array}$} & \multirow{5}{*}{.579} & \multirow{5}{*}{.579} & \multirow{5}{*}{1.765} \\
\hline $\begin{array}{c}\text { Entertainm- } \\
\text { ent }\end{array}$ & .271 & .046 & .311 & $5.834 * * *$ & .462 & 2.162 & & & & \\
\hline Educational & .162 & .060 & -.071 & $2.709 * *$ & .496 & 2.017 & & & & \\
\hline Deviating & .358 & .085 & & $6.219 * * *$ & .494 & 2.024 & & & & \\
\hline Aesthetic & .051 & .052 & .348 & .988 & .557 & 1.769 & & & & \\
\hline
\end{tabular}

Note: $* \mathrm{p}<0.05, * * \mathrm{p}<0.01, * * * \mathrm{p}<0.001$

If you take a close look at the analysis result of hypothesis 1, firstly, the nonstandardization factor of entertainment experience was 0.271 , which is statistically significant in significance level $\mathrm{p}<0.001$. Therefore, entertainment experience has a positive effect on experience satisfaction, and hypothesis 1-1 stands true.

Secondly, the non-standardization factor of educational experience was 0.162 , 
which is statistically significant in significant level $p<0.01$. Therefore, educational experience has a positive effect on experience satisfaction, and hypothesis 1-2 stands true.

Thirdly, the non-standardization factor of deviating experience was 0.358 , which is statistically significant in significant level $p<0.001$. Therefore, deviating experience is significant and has a positive effect to the experience satisfaction, and hypothesis 1-3 stands true. Fourthly, the relationship between the aesthetic experience and experience satisfaction is not statistically significant, and hypothesis 1-4 does not stand true.

In summary, entertainment, educational, and deviating experience are all factors that increase experience satisfaction. Aesthetic experience does not increase the experience satisfaction; therefore, exhibition experience with strong aesthetic factors such as color and lighting is needed.

Table. 6: Analysis results of Experience Satisfied and Buying Intention

\begin{tabular}{|c|c|c|c|c|c|c|c|c|c|c|}
\hline \multirow[t]{2}{*}{ Model } & \multicolumn{2}{|c|}{$\begin{array}{c}\text { Non-standar- } \\
\text { dization } \\
\text { Factor }\end{array}$} & \multirow{2}{*}{$\begin{array}{c}\text { Stand- } \\
\text { ardiza- } \\
\text { tion } \\
\text { Factor } \\
\text { Beta }\end{array}$} & \multirow[t]{2}{*}{$\mathbf{t}$} & \multicolumn{2}{|c|}{$\begin{array}{c}\text { Collinearity } \\
\text { Statistic }\end{array}$} & \multirow{2}{*}{$\begin{array}{c}\text { Analysis } \\
\text { of } \\
\text { F }\end{array}$} & \multirow{2}{*}{$\begin{array}{c}\mathbf{R} \\
\text { Square }\end{array}$} & \multirow{2}{*}{$\begin{array}{c}\text { R } \\
\text { Square } \\
\text { Variation }\end{array}$} & \multirow{2}{*}{$\begin{array}{c}\text { Durbin } \\
\text {-Watson }\end{array}$} \\
\hline & B & $\begin{array}{c}\text { Standard } \\
\text { Error }\end{array}$ & & & $\begin{array}{l}\text { Tole- } \\
\text { rance }\end{array}$ & VIF & & & & \\
\hline (Constant) & -.606 & .216 & & -2.803 & & & \multirow{2}{*}{$\begin{array}{c}398.735 \\
* * *\end{array}$} & \multirow[b]{2}{*}{.591} & \multirow[b]{2}{*}{.591} & \multirow[b]{2}{*}{2.701} \\
\hline $\begin{array}{l}\text { Experience } \\
\text { Satisfaction }\end{array}$ & 1.011 & .051 & .769 & $\begin{array}{c}19.698 \\
* * *\end{array}$ & 1.000 & 1.000 & & & & \\
\hline
\end{tabular}

Note: $* \mathrm{p}<0.05, * * \mathrm{p}<0.01, * * * \mathrm{p}<0.001$

If you take a close look at the analysis result of hypothesis 2, the nonstandardization factor of experience satisfaction was 1.011, which is statistically significant in significant level $\mathrm{p}<0.001$, according to Table 6 . Therefore, experience satisfaction after exhibition experience has a positive effect on purchase intent, and hypothesis 2 stands true.

In summary, entertainment, educational, and deviating experience all increase experience satisfaction and have positive effect on purchase intent. Therefore, if the three factors are high, it can be said that purchase intent is also high.

\section{Conclusion}

The purpose of this research is to suggest future direction of corporate promotion exhibition halls, by understanding how the such exhibition experience affects experience satisfaction and purchase intent. Using the four experience factors that 
Pine \& Gilmore suggested(Entertainment, Educational, Deviating, and Aesthetic experience), we have conducted an empirical analysis to determine the relationship between the exhibition experience and experience satisfaction.

The result of the research proves that amongst the four factors of exhibition experience, the three factors(entertainment, educational, deviating) have significant effect on experience satisfaction. The result of the empirical analysis means that aesthetic factors such as design, color and lighting should be enhanced to increase the experience satisfaction of the audience, which can lead to positive behaviors, corporation's image and brand value.

In addition, since entertainment, educational, and deviating experience increased experience satisfaction and had a positive effect on purchase intent, if the three factors are high, it can be said that purchase intent is also high.

The academical significance of this research is to empirically analyze and identify the relationship between the experience satisfaction via exhibition experience and the purchase intent, as corporate promotion exhibition hall target. Thus, this research has proved that there is a need to improve corporation's image, communication with the customers, and product marketing via exhibition development, with an active experience-oriented exhibition that focuses more on the aesthetic factor.

For the follow-up study, in order to provide the best exhibition experience to the audience who visit the corporate promotion exhibition hall, it needs to add different variables other than the four experience factors, including information desk, how to guide, etc.

(This research was support by the Tong-Myong University of Research Grants 2018A024.)

\section{References}

Bong-Su, P., Young Hun, O., Mi suk, P. \& Kyung Hee, J. (2016). The meaning of experiences in the permanent return movement of Sakhalin Koreans. Asia-Pacific Journal of Educational Management Research, 1(1), 109-114.

Bugawa, A.M., Al-Jayyousi, O.R., Alsultanny Y.A., Bhandari, M.P. \& Mirzal, A. (2018). An Overview on Professional Education Development in Technology Management: The Experience of Arabian Gulf University. Asia-Pacific Journal of Educational Management Research, 3(1), 39-48.

Hae-Jin, S. (2007). A Study on Characteristics of Exposition Space for Revitalization of Company Brand. Myung-Ji Univeristy Master's Thesis, 22-24.

Hye-Jin, Gw. (2007). A Study on Display of Museum Exhibition for Synaesthetic Experience. Hong-Ik University Master's Thesis, 8. 
Jeang-Nam, Kim. (2018). Research on the Sexual Minority Counseling Experience of the Counselors. Asia-Pacific Journal of Educational Management Research. 3(2), 9-14.

Jing-Young, H. (2013). A Study on the Corporate Exhibition Center Visitors' Behavioral Intentions of Experience Economy Theory. Seo-Gang University Master's Thesis, 8-15.

Jung-Suk, Hy. (2002). Structure of Exhibition Scenario and Space Arrangement Programming in the Enterprise Museum. Seong-Gyun-Gwna University Master's Thesis, 5 .

Mi-Hee, H. (2016). On the Effect of College Students' Overseas Experiences on their Global Leadership Ability. Asia-Pacific Journal of Educational Management Research, 1(1), 121-126.

Mi-Ran, S. (2012). A Study of the Design for the Coporate PR office applying Experoential economic theory and the $4 \mathrm{Es}^{\prime}$ Expressive feature. Hong-Ik University Master's Thesis, p.15.

Myeong-Hyeon, H., Jae-Woon, L., Van Thanh, Tr., Eun-Young, L., Min-Sang, K. \& Dong-Ho, K. (2017). Comparison of User Experiences of Augmented Realitybased Car Maintenance Contents Using Mobile Devices and Hololens. Asia-pacific Journal of Convergent Research Interchange. SoCoRI. ISSN : 2508-9080 (Print); 2671-5325 (Online), 3(4), 57-63.

Seung-Wan, J. \& Lee-Sang, J. (2019). The Effect of Exhibition Experience on the Intention of Purchase. International Journal of Smart Business and Technology, $7(2), 1-6$.

Seo-U, Ch. (2014). The Influence of Theme Park Service's Experience on Brand Equity. Han-Yang University Master's Thesis, 14.

Su-Ji, K. (2015). A Study on the Relations among Experience elements, Satisfaction and Behavioral intention. Gyeong-Hui University of Master's Thesis, 10.

Suk-Young, H. \& Seo-Ho, Um. (2005). Verification on Experience Realms of Pine and Gilmore. The Tourism Sciences Society of Korea, 29(2), 131-148.

Su-Kyung, P. (2007). The Effect of Experience Marketing on Consumer Response: Pine \& Gilmore's Perspective. HanKuk University of Foreign Studies Master's Thesis, 17.

Su-Young, K. (2014). A study on Improving Exhibit Experience for Hands-on Exhibition Design. Han-Yang Univeristy Master's Thesis, 8. 